\title{
Sensory Evaluation of Choy Sum (Brassica chinensis L. var. parachinensis) Grown with Mineral and Organic Fertiliser in Kampar, Perak, Malaysia
}

\author{
J.L. Tan ${ }^{12^{*}}$, D.L. Wong3 3 and M.K. Ong3 3 \\ ${ }^{1}$ Department of Zoology, Faculty of Science, University of South Bohemia, České Budějovice, Czech Republic \\ ${ }^{2}$ Department of Biochemistry and Physiology, Institute of Entomology, Biology Centre CAS, České Budějovice, Czech \\ Republic \\ ${ }^{3}$ Department of Agricultural and Food Science, Faculty of Science, Universiti Tunku Abdul Rahman, Perak, Malaysia
}

\begin{abstract}
Consumers perceive organic vegetables as better in taste and quality compared to conventional vegetables. Therefore, this study aims to determine the sensory difference of choy sum (Brassica chinensis L. var. parachinensis) grown with organic fertiliser and mineral fertiliser without the input of synthetic pesticides. A survey was carried out to determine Malaysian consumer sensory perception on organic and conventional leafy vegetables. The choy sum was planted in a Complete Randomised Block Design (CRBD), with input of organic fertiliser (T1, rate: $1500 \mathrm{~kg} / 4046 \mathrm{~m}^{2}$ ) and mineral fertiliser (T2, rate: $63 \mathrm{~kg} / 4046 \mathrm{~m}^{2}$ ) in a 7 -day interval. It was harvested for sensory evaluation at maturity. Seventy-five untrained panellists were selected for the sensory test. The moisture content was analysed using oven drying method, while the sugar and colour analysis was carried out using a brix refractometer and a spectrophotometer, respectively. The survey confirmed that most consumers believe that the sensory attributes of organic vegetables are better than conventional vegetables. However, sensory evaluation shows that there is no significant difference $(\mathrm{P}>0.05)$ in all sensory attributes tested except for greenness. T2 were significantly greener $(\mathrm{P}<0.05)$ than $\mathrm{T} 1$. There were also no significant differences $(\mathrm{P}>0.05)$ found between the treatments in the sugar, moisture and colour analysis.
\end{abstract}

Keywords: consumer perception on organic; food science; organic and conventional vegetables; sensory evaluation of leafy vegetable

\section{INTRODUCTION}

The increasing popularity of sustainability has led to increased popularity in organic food. This is mainly due to the benefits of organic farming for society, namely positive impact on the environment and better food quality (Haering et. al., 2001; Watts \& Williamson, 2015). Mie et al. (2017) review found that organic food has a positive impact on human health, such as reducing risk of allergic disease, overweight and obesity, and less exposure to pesticide residues that can affect child cognitive development. In addition to health benefits, organic fertilisers were able to achieve comparable yields as a replacement for mineral fertilisers (Herencia et. al., 2007; Zahradnik \& Petrikova, 2007). However, this is not always the case, it depends on the soil type and the type of organic fertilisers. In many cases, a combination of organic and mineral fertilisers resulted in a higher yield as compared to solely depending on single type of fertilisers (Ullah et. al., 2008; Baghdadi et. al., 2018; Sofyan et al., 2019). Tittonell et al. (2008) findings suggested that organic farm inputs, such as animal manure, cannot provide sufficient nutrients in degraded soils and thus combining with mineral fertilisers will encourage the use of organic inputs among smallholder farmers. This will 
eventually assist in soil restoration and generate higher crop productivity in the future.

Besides the health and environmental benefits of organic food, consumers believe that organic food tastes better than conventional food (Gopalakrishnan, 2019). Through verbal communication with Malaysian consumers, organic vegetables were perceived as better in taste, such as fresher, crunchier and sweeter, compared to conventional vegetables. Similar findings were found among Irish consumers (Tobin et al., 2013). Shafie and Rennie (2012) suggested that consumer perception on food safety was the main factor driving them in favour of organic food sensory attribute. Furthermore, the sensory evaluation of Zhao et al. (2007) and Tobin et al. (2013) found no significant difference between organic and conventional vegetables, although consumers initially perceived otherwise. However, organic carrots and potatoes were found to be better in taste and aroma, but yield was significantly lower (Rembialkowska, 2003). The sensory analysis of Jalpa and Maneesha (2015) also found that organic food was better in aroma, texture and taste. These contradicting findings may be due to several factors, such as the demographic of the consumers, type of vegetables and planting method. Thus, this study is to determine the sensory differences of choy sum (Brassica chinensis L. var. parachinensis) grown with organic input (composted chicken manure) and mineral input without any input of synthetic pesticides. Choy sum were chosen because it is one of the commonly consumed leafy vegetables in Malaysia. The findings of this study will be shared with consumers, and if no significant sensory differences are found, organic vegetable consumers are recommended to accept pesticide-free vegetables grown with mineral or integrated fertilisers system. This is because organic fertilisers may not have sustainable yields for smallholder farmers in degraded soil areas, therefore, mineral fertilisers or an integrated fertiliser system may be more feasible.

\section{MATERIALS AND METHODS}

\section{A. Survey on the Consumer Perception of Vegetables Grown with Mineral and Organic Fertiliser}

A simple online survey was conducted using Google form to collect the perception of the public about the sensory attribute of leafy vegetables grown using mineral and organic fertiliser. The survey was conducted from December 2019 to January 2020. The target respondents were from various states in Malaysia. The survey consists of 6 closed-ended questions which cover general differences, the appearance (greenness), the texture (fibrous and crunchiness), the sweetness and the moisture level of the leafy vegetables grown with mineral and organic fertilisers.

\section{B. The Planting of the Vegetables}

The planting of the choy sum (Brassica chinensis L. var. parachinensis) was carried out in the Agricultural Park (N $4^{\circ} 20^{\prime} 31.02072$ ", E $\left.101^{\circ} 8^{\prime} 24.5454^{\prime \prime}\right)$ of Universiti Tunku Abdul Rahman, Perak Campus in Kampar, Malaysia in February 2020 to March 2020. Seven wooden planting boxes, size of $1 \mathrm{~m}^{2}$ each, were filled with top soil and layout in Complete Randomised Block Design (CRBD). There were three replicates treated with mineral fertilisers, three other replicates treated with organic fertilisers, and one control box was not treated with any fertilisers.

Each box was broadcasted with approximately $8 \mathrm{~g}(\sim 500$ seeds/g) of commercial choy sum seeds (Leckat, 008 Wang Bujang, China). Seeds were mixed with sand before broadcast to ensure uniform seed distribution (Tan et al., 2020). The first application of fertilisers was done 4 days after sowing (DAS) and retreatment was carried out at a 7-day interval until vegetables were harvested. Mineral fertiliser (Nitrophoska NPK Green 15-15-15, EuroChem Agro GmbH, Germany) was applied at the rate of $63 \mathrm{~kg} / 4046 \mathrm{~m}^{2}$ while the organic fertiliser (self-composted chicken manure) was applied at the rate of $1500 \mathrm{~kg} / 4046 \mathrm{~m}^{2}$. The application rate of these fertilisers follows the local farmer's practice. Seedlings were thinned at 14 DAS to allow spacing between plants for growth. Irrigation was carried out using overhead water sprinklers and hand weeding was carried out to control weeds whenever necessary. The vegetables were grown without pesticides.

\section{Sensory Evaluation}

The choy sum was freshly harvested for sensory evaluation. Choy sum was only harvested when it began flowering, indicating that the plant had reached maturity (approximately 30 days). The harvested choy sum was washed with tap water and cut into pieces of almost similar 
size. The prepared raw vegetables were added to boiling tap water in a stainless-steel pot and cooked for about $2 \mathrm{~min}$. The vegetables were boiled because it is one of the most preferred way of cooking vegetables (Clarke \& Evans, 2015). Additionally, no additional other ingredients were added, preserving the original taste of the vegetables. The vegetables were ready for the panellists once they were tender-crisp after 2 min.

Seventy-five untrained panellists were selected among the students and staff at the Universiti Tunku Abdul Rahman (UTAR) Perak Campus. Two coded samples (i.e., cooked choy sum) and a cup of rinsing water were prepared for each panellist. The panellists were to note the appearance (i.e., greenness), the taste (i.e., sweetness and juiciness) and the texture (i.e., crunchiness and hardness) of the given samples. They were required to choose their most preferred choice among the two samples according to each of the attributes.

\section{Moisture Analysis}

Three freshly harvested choy sum from each treatment were used for moisture analysis. The samples were weighed as soon as possible after harvest using an electronic laboratory balance (ME1002, Mettler Toledo, Switzerland) to obtain the fresh weight. The samples were placed in a drying oven (MMT-IN110, Memmert, Germany) at $40^{\circ} \mathrm{C}$ for $48 \mathrm{~h}$ before measuring the dry weight using the same electronic balance. The moisture content of the samples was calculated using the formula (deMan et al., 2018):

$$
\% \text { Moisture }=\frac{\mathrm{M}_{\text {Initial }}-\mathrm{M}_{\text {Dried }}}{\mathrm{M}_{\text {Initial }}} \times 100
$$

\section{E. Brix and Colour Analysis}

The sweetness of the samples was determined by the brix value and was measured using a brix refractometer (PAL-3, ATAGO Co. Ltd., Japan). The refractometer was calibrated with distilled water prior to the actual measurement. The vegetable samples for each treatment were blended separately using an electrical blender (MX-GM1011, Panasonic, Japan) to form juice for brix analysis. A few drops of the juice were placed on the refractometer to obtain the ${ }^{\circ}$ Brix value.

The colour analysis was done using a portable handheld spectrophotometer (CM-6ood, Konica Minolta, Inc., Japan).
The portable handheld spectrophotometer was calibrated prior to actual measurement. The spectrophotometer was placed on top of the vegetable's leaf sample to obtain the lightness $\left(\mathrm{L}^{*}\right)$ and the chromaticity coordinates $\left(\mathrm{a}^{*}\right.$ and $\left.\mathrm{b}^{*}\right)$ value.

\section{F. Statistical Analysis}

IBM Statistical Product and Service Solutions (SPSS) version 23.0 was used for the data analysis. Non-parametric pairwise comparison, Mann-Whitney $U$ test was used to analyse the data collected from the sensory evaluation. The data from moisture, brix and colour analysis were subjected to one-way analysis of variance (ANOVA) and post hoc test, namely Tukey HSD. Prior to ANOVA, Shapiro-Wilks (S-W) $W$ test was used to evaluate the assumption of normality. If the assumption of normality was violated $(\mathrm{P}<0.05)$, the nonparametric alternative of one-way ANOVA, the KruskalWallis $\mathrm{H}$ test was used and Mann-Whitney $U$ test was used as the post hoc test for the Kruskal-Wallis $\mathrm{H}$ test.

\section{RESULTS AND DISCUSSION}

\section{A. The Consumer Survey on Sensory Perception of Organic and Conventional Grown Leafy Vegetables}

An online survey was conducted to determine the perception of consumers about leafy vegetables grown with organic and mineral fertilisers. There were a total of 560 respondents and 462 of them (82.5\%) agreed that leafy vegetables grown with organic fertilisers (OF) will exhibit different sensory attributes from those grown with mineral fertilisers (MF). Among this majority of the respondents, most of them perceived that OF will produce vegetables that are better in all sensory attributes (Table 1). This is not surprising as consumers around the world have similar perceptions where organic products are more superior in taste and quality (Zhao et. al., 2007; Rahman et al., 2021). However, Shafie and Rennie (2012) and Rahman et al. (2021) pointed out that environmental concerns and food safety may be the factors which lead consumers to believe that organic vegetables were better. This is because organically grown plants are not planted with synthetic pesticides that may have adverse effect on human health as well as the environment. 
Table 1. Consumer's survey on sensory perception of leafy vegetables grown with organic or mineral fertilisers

\begin{tabular}{lcc}
\hline Sensory attribute & \multicolumn{2}{c}{ Vote in favour (\%) } \\
& MFV & OFV \\
\hline Appearance, such as greener, fresher or healthier & 30.3 & 69.7 \\
Texture, such as level of fibre & 41.9 & 58.1 \\
Crunchiness & 31.5 & 68.5 \\
Sweetness & 29.6 & 70.4 \\
Juiciness and Moisture & 32.8 & 67.2 \\
\hline
\end{tabular}

Note: mineral fertilisers grown vegetable (MFV), organic fertilisers grown vegetable (OFV)

\section{B. The Sensory Evaluation}

The Mann-Whitney $U$ test was used to compare the panellists' preferred choice of choy sum (Table 2). The panellists' choice will be marked as " 1 " while the other "o". Based on sensory evaluation, there is no significant difference $(\mathrm{P}>0.05)$ in the sweetness, juiciness, crunchiness and hardness of the vegetables grown with organic or mineral fertilisers. This was consistent with other similar studies that found no significant difference in the sensory properties of vegetables grown organically or using OF versus conventionally produced vegetables (Tobin et. al., 2013; Zhao et. al., 2007; Jalpa \& Maneesha, 2015; Rodriguez et. al., 2001; Basker, 1992). Furthermore, Rodriguez et al. (2001) found that there was also no difference in flavour and taste for vegetables produced using an integrated system (i.e., mixture of organic and mineral fertilisers). Conventional carrots were found to be better in terms of sweetness (Haglund et al., 1998) and in this study, choy sum grown with mineral fertilisers gets a higher vote in terms of sweetness (Table 2).

Sugar content analysis using a brix refractometer, indicates that choy sum grown with OF $\left(0.57 \pm 0.47^{\circ} \mathrm{Bx}\right)(\mathrm{T} 1)$ was lower than those supplied with MF (0.77 $\left.\pm 0.63^{\circ} \mathrm{Bx}\right)(\mathrm{T} 2)$. However, statistical analysis using the Kruskal-Wallis $\mathrm{H}$ test and MannWhitney $U$ test found no significant difference $(\mathrm{P}>0.05)$ in the brix value of T1 and T2 (Table 3). The sugar content was analysed using a brix refractometer to further confirmed with analytical tools that there are no significant differences in term of sweetness for this vegetable grown with different types of fertilisers. In a similar study, the comparison of sugar content for several fruits (i.e., apple, pear and blackcurrant) and vegetables (i.e., carrot, beetroot and celery) planted organically and conventionally generates an inconsistence result, but no significant difference $(\mathrm{P}>0.05)$ was observed through statistical analysis (Gąstoł et al., 2011). A review by Rahman et al. (2021) also found inconsistency in the sugar content between vegetables and fruits grown organically and conventionally. Therefore, it is suspected that the sugar content is most probably influenced by the type of crops, crop varieties, type of treatments and also harvest maturity. Despite these factors, the difference in brix values may not be detectable by human panellist in a sensory test, thus resulting in statistically not significant (Rodriguez et. al., 2001; Tobin et. al., 2013; Zhao et. al., 2007; Basker, 1992). In addition to sugar content, moisture content was also analysed and there was no significant difference $(\mathrm{P}>0.05)$ between $\mathrm{T} 1, \mathrm{~T} 2$ and control (Table 3). In the sensory test, no significant difference (P > 0.05) was also found in the juiciness of the vegetable sample (Table 2). The moisture level for all treatments was similar because all plants were of the same variety and were supplied with sufficient water through irrigation and rain. Furthermore, the planting medium used was clayey loam soil that was able to retain sufficient water. Unlike perceived by consumers that organic vegetables are juicier (Table 1), the negligible difference in moisture by sensory test and analysis showed that the type of fertilisers used has minimal to no influence on the juiciness. Therefore, most consumers who promote organic vegetables are juicier may be a result of a personal psychological effect.

According to Table 2, there was a significant difference $(\mathrm{P}<$ o.05) in greenness or general appearance of the vegetables. In contrast, the colour analysis of the sample does not shows significant difference $(\mathrm{P}>0.05)$ in the lightness, the red/green coordinate and yellow/blue coordinate (Table 3). This indicates that the greenness of the vegetables does not actually vary between each other. However, by the naked eye 
of the panellists, most of them perceive that T2 was greener than T1. This result further debunked the perception of most consumers (Table 1 ) that organic vegetables are greener than conventional vegetables as T2 was vegetables grown with mineral fertilisers. The reason for this may be that the vegetables supplied with mineral fertiliser appear slightly greener probably due to higher nitrogen nutrients in the plant. This is because the mineral fertilisers supplied in this study comprised of $15 \%$ of nitrogen, which is much higher than composted chicken manure which usually contain less than $4 \%$ of nitrogen (Rubeiz et. al., 1993; Mkhabela, 2004). The higher nitrogen supplied to vegetables will lead to an increase in chlorophylls which will make the leaf appear slightly greener (Becker et al., 2015). However, the spectrophotometer did not detect significant differences in the colour of the samples including the control (Table 4); therefore, this indicates that the colour of the leaf for short-term crops like choy sum may be highly dependent on the cultivars or variety.

Based on the findings of the sensory analysis, both from the panellists (Table 2) and analytical tools (Table $3 \& 4$ ), shortterm leafy vegetables like choy sum do not exhibit difference in taste, especially sweetness, and appearance, even though they were grown with different types of fertilisers. As reported by Rodriguez et al. (2001), the nutritional analysis of tomatoes grown under conventional, organic or integrated conditions did not exhibit significant difference nutritional values. A review by Bernacchia et al. (2016) reported the same, where cultivation methods have very little influence on the nutritional values of the produce. Therefore, this disproved the beliefs of most consumers, where organic vegetables are more superior than their conventional counterpart (Table 1). Organic vegetable consumers are encouraged to also support pesticide-free conventional vegetables since there are no sensory differences. By doing so, vegetables produced in an integrated fertiliser system will have better demand and thus, motivate smallholder farmers to incorporate organic fertilisers into their production system. In the long-run, smallholder farmers are able to produce financially sustainable yields, and concurrently, their soil can be regenerated with the presence of organic inputs.

Further studies should determine which plant nutrients are highly involved in manipulating the taste, such as sweetness, of fresh produce. Furthermore, in this study, no synthetic pesticide was used throughout the planting process. Therefore, the residue of synthetic pesticides can be taken into account in affecting sensory properties.

Table 2. The panellists' preferred choice $(n=75)$ on choy sum grown with organic-based and mineral-based fertilisers based on different parameters

\begin{tabular}{cccccc}
\hline Treatment & Sweetness & Juiciness & Crunchiness & Greenness & Hardness \\
\hline $\mathrm{T} 1$ & $34^{\mathrm{a}}$ & $36^{\mathrm{a}}$ & $41^{\mathrm{a}}$ & $23^{\mathrm{a}}$ & $33^{\mathrm{a}}$ \\
$\mathrm{T} 2$ & $41^{\mathrm{a}}$ & $39^{\mathrm{a}}$ & $34^{\mathrm{a}}$ & $52^{\mathrm{b}}$ & $42^{\mathrm{a}}$ \\
\hline
\end{tabular}

Note: T1: organic input vegetables, T2: mineral input vegetables. The different superscript alphabets indicate a significant difference $(\mathrm{P}<0.05)$ in Mann-Whitney $U$ test within the column.

Table 3. Brix and moisture analysis of choy sum grown with organic-based and mineral-based fertilisers

\begin{tabular}{ccc}
\hline Treatment & Degree Brix value ( $\left.{ }^{\circ} \mathbf{B x}\right)$ & Moisture content (\%) \\
\hline $\mathrm{T} 1$ & $0.57 \pm 0.47^{\mathrm{ab}}$ & $91.41 \pm 74.65^{\mathrm{a}}$ \\
$\mathrm{T} 2$ & $0.77 \pm 0.63^{\mathrm{a}}$ & $91.33 \pm 74.58^{\mathrm{a}}$ \\
Control & $0.43 \pm 0.37^{\mathrm{b}}$ & $89.91 \pm 73.41^{\mathrm{a}}$ \\
\hline
\end{tabular}

Note: T1: organic input vegetables, T2: mineral input vegetables, control: no nutrients input. The different superscript alphabets indicate a significant difference in Mann-Whitney $U$ test (Degree Brix value) and Tukey HSD (Moisture content) within the column. 
Table 4. Colour analysis of the choy sum grown with organic-based and mineral-based fertilisers

\begin{tabular}{cccc}
\hline Treatment & $\mathbf{L}^{*}$ & $\mathbf{a}^{*}$ & $\mathbf{b}^{*}$ \\
\hline T1 & $42.59 \pm 34.78^{\mathrm{a}}$ & $9.56 \pm 7.81^{\mathrm{a}}$ & $19.36 \pm 15.81^{\mathrm{a}}$ \\
T2 & $42.79 \pm 34.94^{\mathrm{a}}$ & $9.11 \pm 7.44^{\mathrm{a}}$ & $20.06 \pm 16.38^{\mathrm{a}}$ \\
Control & $42.95 \pm 35.07^{\mathrm{a}}$ & $9.24 \pm 7.54^{\mathrm{a}}$ & $20.66 \pm 16.87^{\mathrm{a}}$
\end{tabular}

Note: T1: organic input vegetables, T2: mineral input vegetables, control: no nutrients input, $\mathrm{L}^{*}$ : lightness, $\mathrm{a}^{*}$ : red/green coordinate, $b^{*}$ : yellow/blue coordinate. The different superscript alphabets indicate a significant difference in Tukey HSD within the column.

\section{CONCLUSION}

The survey found that most consumers (82.5\%) agreed that there is a difference in the sensory properties of organic and conventional leafy vegetables. Among these consumers, most of them perceived organic leafy vegetables as superior in sensory attributes compared to their conventionally planted counterparts. However, this was proven otherwise by the finding in this study. In the sensory analysis, there were no significant differences in all of the tested sensory attributes, except for greenness. Furthermore, the sugar and moisture content analysis, as well as the colour analysis also did not find significant differences between the two treatments. Therefore, consumers are encouraged to purchase organic and pesticide-free conventional vegetables as they taste similar. This will also assist in the incorporation of organic inputs into the vegetable production regime of local smallholder farmers.

\section{ACKNOWLEDGEMENT}

The authors acknowledge the support of the Faculty of Science, Universiti Tunku Abdul Rahman, Malaysia. This project was supported by the Department of Agricultural and Food Science, Faculty of Science, Universiti Tunku Abdul Rahman, Malaysia.

\section{REFERENCES}

Baghdadi, A, Halim, RA, Ghasemzadeh, A, Ramlan, MF \& Sakimin, SZ 2018, 'Impact of organic and inorganic fertilizers on the yield and quality of silage corn intercropped with soybean', PeerJ, vol. 6, pp. 1-26.

Basker, D 1992, 'Comparison of taste quality between organically and conventionally grown fruits and vegetables', American Journal of Alternative Agriculture, vol. 7, no. 3, pp. 129-136.

Becker, C, Urlic, B, Spika, MJ, Klaring, H-P, Krumbein, A, Baldermann, S, Ban, SG, Perica, S \& Schwarz, D 2015, 'Nitrogen limited red and green leaf lettuce accumulate flavonoid glycosides, caffeic acid derivatives, and sucrose while losing chlorophylls, B-carotene and xanthophylls', PloS ONE, vol. 10, no. 11, pp. 1-22.

Bernacchia, R, Preti, R \& Vinci, G 2016, 'Organic and conventional foods: Differences in nutrients', Italian Journal of Food Science, vol. 28, pp. 565-578.

Clarke, P \& Evans, SH 2015, 'How do cooks actually cook vegetables? A field experiment with low-income households.', Health Promotion Practice, vol. 17, no. 1, pp. 80-87.

deMan, JM, Finley, JW, Hurst, WJ \& Lee, CY 2018, Principles of Food Chemistry, NY, USA, Springer.

Gąstoł, M, Domagała-Świątkiewicz, I \& Krośniak, M 2011, 'Organic versus conventional - a comparative study on quality and nutritional value of fruit and vegetable juices', Biological Agriculture \& Horticulture: An International Journal for Sustainable Production Systems, vol. 27, no. 34, pp. 310-319.

Gopalakrishnan, R 2019, 'Advantages and nutritional value of organic food on human health', International Journal of Trend in Scientific Research and Development (IJTSRD), vol. 3 , no. 4 , pp. 242-245

Haering, AM, Dabbert, S, Offermann, F \& Nieberg, H 2001, 'Benefits of organic farming for society', in European Conference - Organic Food and Farming, 10-11 May 2001, The Danish Ministry of Food, Agriculture and Fisheries, Copenhagen, Denmark. 
Haglund, A, Johansson, L, Berglund, L \& Dahlstedt, L 1998, 'Sensory evaluation of carrots from ecological and conventional growing systems', Food Quality and Preference, vol. 10, no. 1, pp. 23-29.

Herencia, JF, Ruiz-Porras, JC, Melero, S, Garcia-Galavis, PA, Morillo, E \& Maqueda, C 2007, 'Comparison between organic and mineral fertilization for soil fertility levels, crop macronutrient concentrations, and yield', Agronomy Journal, vol. 99, pp. 973-983.

Jalpa, D \& Maneesha, S 2015, 'Sensory evaluation test of organic and non organic food', Journal of Environmental Research and Development, vol. 9, no. 3A, pp. 857-863.

Mie, A, Andersen, HR, Gunnarsson, S, Kahl, J, Kesse-Guyot, E, Rembialkowska, E, Quaglio, G \& Grandjean, P 2017, 'Human health implications of organic food and organic agriculture: a comprehensive review', Environmental Health, vol. 16, no. 111, pp. 1-22.

Mkhabela, TS 2004, 'Substitution of fertilizer with poultry manure: is this economically viable?', Agrekon, vol. 43, no. 3, pp. 347-356.

Rahman, SME, Mele, MA, Lee, Y-T \& Islam, MZ 2021, 'Consumer preference, quality and safety of organic and conventional fresh fruits, vegetables and cereals', Foods, vol. 10, no. 1, pp. 105-122.

Rembialkowska, E 2003, 'Organic farming as a system to provide better vegetable quality', Acta Horticulturae, vol. 604, pp. 473-479.

Rodriguez, A, Ballesteros, R, Ciruelos, A, Barreiros, JM \& Latorre, A 2001, 'Sensory evaluation of fresh tomato from conventional, integrated and organic production', Acta Horticulturae, vol. 542, pp. 277-282.

Rubeiz, IG, Sabra, AS, Al-Assir, IA \& Farran, MT 1993, 'Layer and broiler poultry manure as nitrogen fertilizer sources for cabbage production', Communications in Soil Science and Plant Analysis, vol. 24, no. 13-14, pp. 1583-1589.

Shafie, FA \& Rennie, D 2012, 'Consumer perceptions towards organic food', Procedia-Social and Behavioral Sciences, vol. 49, pp. 360-367.
Sofyan, ET, Sara, DS \& Machfud, Y 2019, "The effect of organic and inorganic fertilizer applications on N, P-uptake, K-uptake and yield of sweet corn (Zea mays saccharata Sturt)', IOP Conference Series: Earth and Environmental Science, vol. 393, pp. 1-6.

Tan, JL, Ang, KY, Chow, MH, Lee, ETY, Lee, KH, Lee, LY, Ooi, SW, Soh, WC \& Sithambaram, R 2020, 'A preliminary study on reducing the dosage of chemical fertiliser by using empty fruit bunch as soil amendment on the growth of choy sum', ASM Science Journal, vol. 13, pp. 1 - 6.

Tittonell, P, Corbeels, M, van Wijk, MT, Vanlauwe, B \& Giller, $\mathrm{KE}$ 2008, 'Combining organic and mineral fertilizers for integrated soil fertility management in smallholder farming systems of Kenya: Explorations using the crop-soil model FIELD', Agronomy Journal, vol. 100, no. 5, pp. 1511-1526.

Tobin, R, Moane, S \& Larkin, T 2013, 'Sensory evaluation of organic and conventional fruits and vegetables available to Irish consumers', International Journal of Food Science and Technology, vol. 48, no. 1, pp. 157-162.

Ullah, MS, Islam, MS, Islam, MA \& Haque, T 2008, 'Effects of organic manures and chemical fertilizers on the yield of brinjal and soil properties', Journal of the Bangladesh Agricultural University, vol. 6, no. 2, pp. 271-276.

Watts, M \& Williamson, S 2015, 'Agroecology makes sense: economically, socially and environmentally', in Replacing chemicals with biology: phasing out highly hazardous pesticides with agroecology, Pesticide Action Network (PAN) Asia and the Pacific Malaysia, pp. 48-67.

Zahradnik, A \& Petrikova, K 2007, 'Effect of alternative organic fertilizers on the nutritional value and yield of head cabbage', Horticultural Science, vol. 34, pp. 65-71.

Zhao, X, Chambers IV, E, Matta, Z, Loughin, TM \& Carey, EE 2007, 'Consumer sensory analysis of organically and conventionally grown vegetables', Journal of Food Science, vol. 72, no. 2, pp. 87-91. 